\title{
Pengembangan Media Pembelajaran Berbentuk Video Prosedur Penggunaan Ayakan Bertingkat (Granule Sieve) untuk Pembelajaran Blended Learning
}

\author{
Deny Sutrisno ${ }^{1)}$, Barmi Hartesi ${ }^{2)}$ \\ ${ }^{1)}$ Program Studi Farmasi Sekolah Tinggi Ilmu Kesehatan Harapan Ibu Jambi \\ ${ }^{2)}$ Program Studi Farmasi Sekolah Tinggi Ilmu Kesehatan Harapan Ibu Jambi \\ denysutrisno@gmail.com
}

\begin{abstract}
Blended Learning is learning that involves face-to-face and brave learning that requires teaching materials that can be accessed by the brave. The purpose of this study was to create a learning media based on video as a guide to the use of Granule sieves and also to find out the feedback from the video. Methods of developing learning media through computers: (1) analyzing student needs; (2) formulating goals; (3) formulating the ingredients; (4) developing evaluation instruments; (5) writing scripts and taking pictures; (6) taking feedback $(N=57)$. In addition to the six steps, a validation test is also carried out before the field trial. This study result was a video learning that could be used as teaching material in the form of learning videos using granule sieves.
\end{abstract}

Keywords : Video Pembelajaran, Media Pembelajaran, Granule Sieves

\section{PENDAHULUAN}

Blended Learning merupakan pembelajaran yang mengkombinasikan antara tatap muka langsung di kelas dan pembelajaran melalui daring. Pembelajaran ini bermanfaat dalam meningkatkan prestasi dan hasil belajar (Syarif, 2012) Pembelajaran ini sangat diperlukan oleh mahasiswa terutama pada zaman berkembangnya internet pada seperti pada saat ini karena pembelajaran ini dapat memberikan perubahan yang positif (Moskal, Dziuban, \& Hartman, 2013). Diantara perubahan positif tersebut adalah mahasiswa dapat meningkatkan kemampuan pemecahan masdalah (Agustina \& Alviya, 2012).

STIKES Harapan Ibu Jambi memiliki laboratorium Teknologi Farmasi untuk mendukung pembelajaran dan penelitian di bidang teknologi farmasi. Diantara alat-alat yang terdapat pada laboraturium tersebut adalah Ayakan Bertingkat (Granule seive). Ayakan bertingkat adalah ayakan untuk mengukur distribusi ukuran granul dengan metode memisahkan granul berdasarkan ukuran tertentu. Pemisahan dapat terjadi dengan melakukan ayakan dengan ukuran mesh yang berbeda pada setiap ayakan. Sehingga ada beberapa tingkatan ukuran mesh pada ayakan yang kemudian granul akan terpisah disetiap ayakan berdasarkan ukuran masing-masing.
Alat tersebut harus digunakan dengan benar agar tetap terawat dan selalu bisa digunakan saat dibutuhkan baik saat perkuliahan maupun saat penelitian. Penjelasan yang terus menerus tidak akan bisa dilakukan dengan cara yang tatap muka untuk itu diperlukan media pembelajaran yang bisa diakses secara daring sehingga mahasiswa dapat melihatnya saat mereka membutuhkannya.

Media pembelajaran berbasis video memiliki berbagai kelebihan dibandingkan dengan media pembelajaran lainnya. Apabila dibandingkan dengan pembelajaran tanpa video maka pembelajaran dengan media pembelajaran berbentuk dapat memberikan motivasi yang berbeda (Setiawan, 2015). Khususnya untuk pembelajaran yang berbasis Matematika dan Ilmu Pengetahuan Alam, maka penggunaan video pembelajaran akan lebih memotivasi mahasiswa (Pebriani, 2017). Penggunaan media video pembelajaran bisa menambah kemampuan mahasiswa (Isti, 2012). Adanya gambar dan suara pada video pembelajaran dapat meningkatkan hasil belajar dari perkuliahan mahasiswa (Sugandi, 2012).

Berdasarkan latar belakang yang telah dijelaskan maka peneliti melakukan pengembangan media pembelajaran daring berbentuk video sebagai petunjuk penggunaan ayakan bertingkat. Penelitian ini juga bertujuan untuk mengetahui umpan balik dari video 
tersebut. Manfaat dari penelitian ini adalah dapat digunakan sebagai bahan pembelajaran pada perkuliahan.

\section{METODE PENELITIAN}

Penelitian ini adalah penelitian pengembangan. Pengembangan video pembelajaran ini melalui 6 langkah pengembangan (Asyhar 2011) yakni: (1) menganalisa kebutuhan mahasiswa; (2) merumuskan tujuan pengembangan video; (3) merumuskan butir-butir materi untuk video; (4) menyusun instrumen evaluasi perbaikan video; (5) menulis naskah dan melakukan pembuatan video; (6) melakukan pengambilan umpan balik dari mahasiswa. Selain proses diatas Validasai ahli juga dilakukan terhadap naskah media/ prototipe yang sudah disusun. Jenis validasi yang dilakukan peneliti adalah adalah validasi ahli dengan meminta penilaian hasil video yang telah dibuat oleh orang yang bekerja di bidang IT dan dosen di bidang Teknologi Farmasi. Video pembelajaran yang sudah disunting diperlihatkan kepada seorang validator. Validator kemudian memeriksa dan memberi saran untuk perbaikan video pembelajaran ini.

Pada proses analisa kebutuhan mahasiswa didapatkan kesimpulan bahwa kebutuhan mahasiswa adalah media pembelajaran yang selalu diakses oleh mahasiswa. Analisa kebutuhan ini dilakukan dengan mewawancara kepala Laboratorium STIKES Harapan Ibu Jambi dan dosen pengampu mata kuliah di bidang teknologi farmasi.

Proses selanjutnya adalah merumuskan tujuan pengembangan video. Proses ini dilakukan bersama dosen pengampu mata kuliah di bidang teknologi farmasi dan laboran laboraturium teknologi farmasi STIKES Harapan Ibu Jambi. Tujuan pengembangan video ini adalah membuat video pembelajaran untuk menjelaskan tutorial penggunaan ayakan bertingkat yang dapat dimengerti oleh mahasiswa.

Kemudian proses perumuskan butir-butir materi untuk video dilakukan bersama laboran laboratorium Teknologi Farmasi. Laboran adalah orang yang berpengalaman dalam penggunaan alat tersebut. Selain itu ia juga mengetahui kesalahan apa saja yang sering dilakukan oleh mahasiswa dalam penggunaan alat tersebut.

Proses berikutnya adalah penyusunan instrumen evaluasi. Kisi-kisi angket umpan balik dapat dilihat pada Tabel 1. Skala penilaian angket adalah skala Guttman dengan jawaban "Iya" dan "Tidak". Hasil angket respon direkap secara presentase pada tiap butir item. Angket ini bertujuan untuk mengetahui respon mahasiswa mengenai video ini.

Tabel 1. Kisi-kisi Angket Respon Media Pembelajaran

\begin{tabular}{|c|c|c|}
\hline Variabel & No & Pertanyaan \\
\hline \multirow{7}{*}{$\begin{array}{c}\text { Pengguna } \\
\text { an video } \\
\text { pembela- } \\
\text { jaran }\end{array}$} & 1 & $\begin{array}{l}\text { Apakah kamu dapat } \\
\text { memahami materi } \\
\text { yang disajikan } \\
\text { dengan video ini? }\end{array}$ \\
\hline & 2 & $\begin{array}{l}\text { Apakah tampilan } \\
\text { (gambar, warna, ani- } \\
\text { masi, dll) pada video } \\
\text { ini sudah baik? }\end{array}$ \\
\hline & 3 & $\begin{array}{l}\text { Apakah kamu bermi- } \\
\text { nat untuk mengikuti } \\
\text { kegiatan belajar } \\
\text { dengan menggunakan } \\
\text { video ini? }\end{array}$ \\
\hline & 4 & $\begin{array}{l}\text { Apakah materi yang } \\
\text { terdapat pada video } \\
\text { ini sudah baik? }\end{array}$ \\
\hline & 5 & $\begin{array}{l}\text { Apakah belajar } \\
\text { dengan menggunakan } \\
\text { video bermanfaat } \\
\text { bagi kamu? }\end{array}$ \\
\hline & 6 & $\begin{array}{l}\text { Apakah materi yang } \\
\text { lain perlu disajikan } \\
\text { dengan menggunakan } \\
\text { video seperti ini? }\end{array}$ \\
\hline & 7 & $\begin{array}{l}\text { Apakah materi yang } \\
\text { ada pada video ini } \\
\text { perlu dijelaskan kem- } \\
\text { bali oleh dosen? }\end{array}$ \\
\hline
\end{tabular}

Sumber: (Yamasari, 2010)

Kemudian proses pembuatan naskah video. Proses ini dilakukan oleh laboran dan direvisi oleh validator ahli materi yaitu dosen pengampu mata kuliah.

Proses pengambilan gambar untuk video pembelajaran ini dilaksanakan di laboratorium Teknologi Farmasi STIKES Harapan Ibu Jambi. Tim pembuatan video pembelajaran ini terdiri dari penulis naskah video pembelajaran, pembawa acara atau host yang bertugas memperagakan penggunaan alat ayakan bertingkat, petugas perekam gambar dan suara video pembelajaran dan petugas penyunting 
video yang menggabungkan gambar dan suara hasil pengambilan gambar.

Alat yang digunakan dalam penelitian ini adalah ayakan bertingkat, kamera, perekam suara dan Komputer dengan softwere video editor. Bahan yang digunakan adalah granul sebagai bahan penggunaan alat ayakan bertingkat.

Data umpan balik diperoleh dari mahasiswa semester 1 Program Studi Farmasi STIKES Harapan Ibu Jambi sebagai koresponden $(\mathrm{N}=57)$. Mahasiswa ini belum pernah menggunakan alat ayakan bertingkat ini. Mahasiswa tersebut dipertontonkan video pembelajaran di kelas. Kemudian mereka diminta untuk mengisi form online untuk mendapatkan data umpan balik dari mahasiswa.

\section{HASIL DAN PEMBAHASAN}

Hasil penelitian ini berupa video pembelajaran penggunaan ayakan bertingkat. Video didahului dengan pembukaan singkat, kemudian penjelasan bagian-bagian alat ayakan bertingkat dan dilanjutkan penjelasan langkah-langkah cara penggunaannya. Alur video pembelajaran dapat dilihat pada gambar 1 .

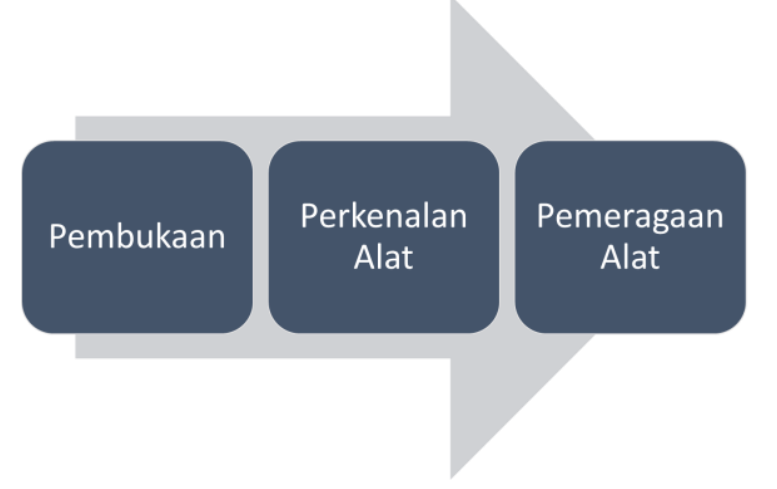

Gambar 1. Alur Video Pembelajaran

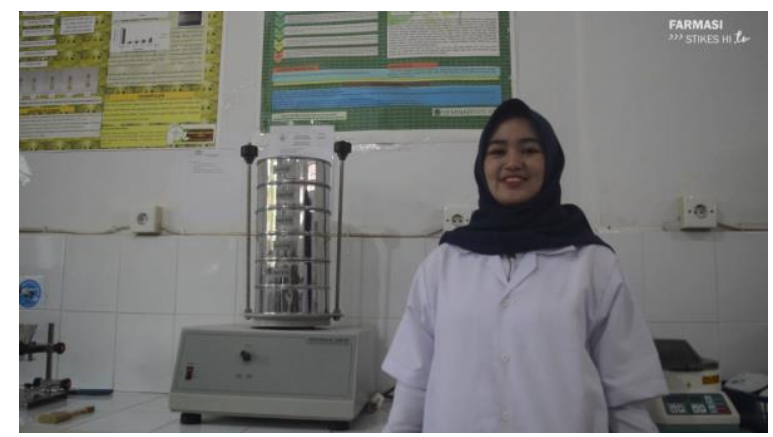

Gambar 2. Potongan Gambar Pembukaan Video

Bagian awal video diperlihatkan mahasiswi sebagai pembawa acara atau host dengan memakai jas lab sedang berdiri di depan alat ayakan bertingkat. Pembawa acara menarik perhatian penonton untuk memperhatikan kelanjutan video mereka agar memahami cara menggunakan alat tersebut. Bagian ini dapat dilihat pada gambar 2 .

Selanjutnya adalah perkenalan alat ayakan bertingkat. Potongan gambar video dapat terlihat pada gambar 3, 4 dan 5. Ayakan bertingkat terdiri dari berbagai ayakan yang memiliki saringan dengan ukuran masingmasing. Ukuran tersebut disebut mesh. Ayakan tersebut disusun dan didudukan pada alat pengayak. Alat tersebut terdapat tombol power untuk menghidupkan atau mematikan alat. Kemudian terdapat palang pengunci yang membuat saringan mesh tidak lepas pada saat berputar. Selain itu terdapat saringan mesh yang menyaring sampel yang akan diuji sesuai dengan metode yang digunakan.

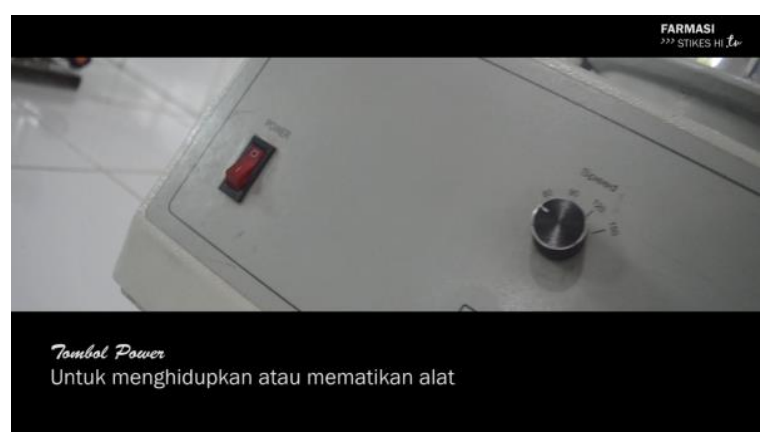

Gambar 3. Potongan Gambar Bagian Tombol Power Alat Ayakan Bertingkat

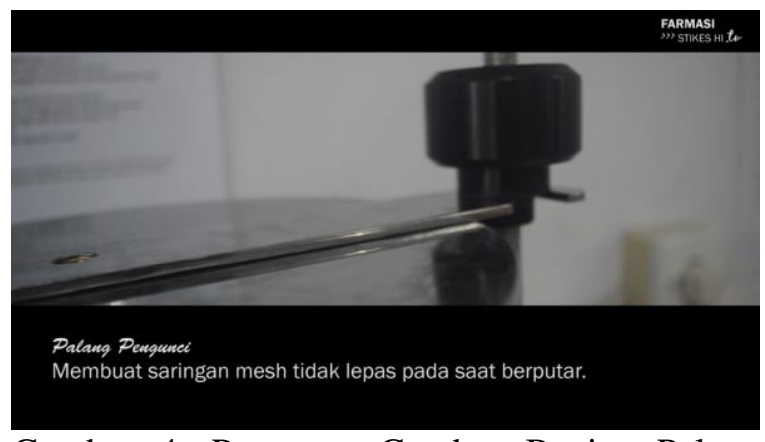

Gambar 4. Potongan Gambar Bagian Palang Pengunci Alat Ayakan Bertingkat.

Pada bagian perkenalan alat ayakan bertingkat diperlihatkan satu per satu bagian alat tersebuts. Pada setiap bagian alat ditampilkan gambar video dan narasi berupa tulisan mengenai nama dan fungsi bagian alat yang sedang ditampilkan. Pada gambar 3, 4 dan 5 dapat terlihat gambar terbagi dua bagian yaitu gambar bergerak yang menunjukkan mesh dan pada 
bagian bawahnya adalah kegunaan bagian alat tersebut. Lalu video berlanjut ke bagian-bagian alat ayakan bertingkat lain sekaligus fungsinya masing-masing.

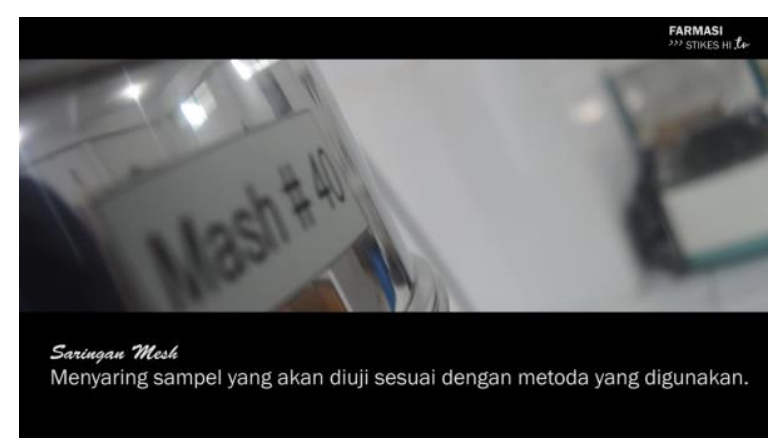

Gambar 5. Potongan Gambar Bagian Saringan Mesh Alat Ayakan Bertingkat.

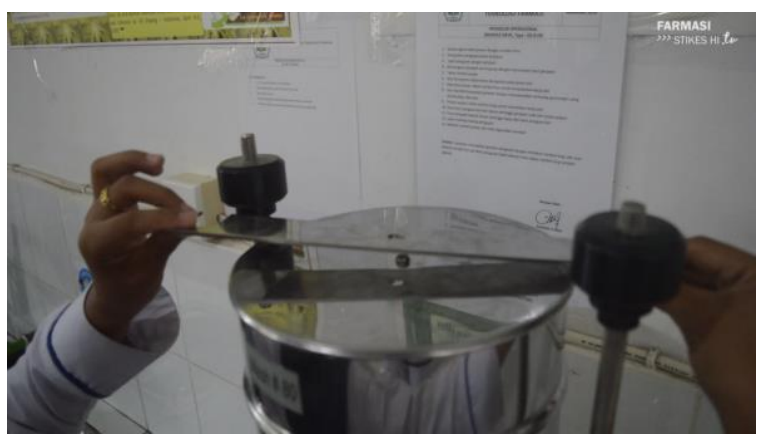

Gambar 6. Potongan Gambar Bagian Cara Memasang Palang Pengunci Ayakan Bertingkat.

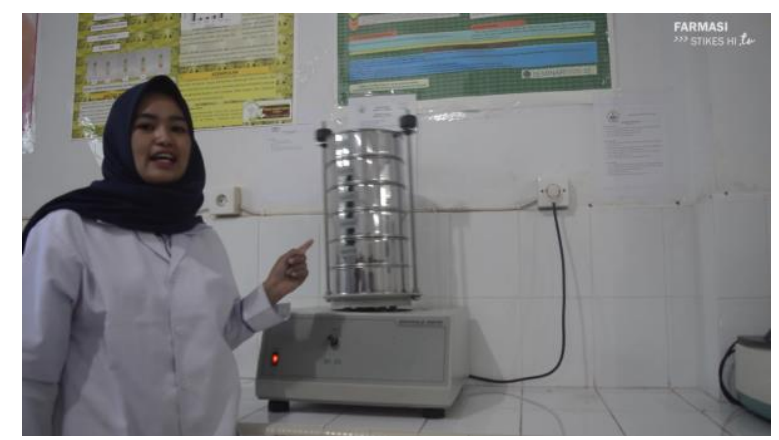

Gambar 7. Potongan Gambar Bagian Cara Penggunaan Ayakan Bertingkat.

Kemudian adegan berlanjut ke pemeragaan penggunaan alat ayakan bertingkat. Pada gambar 6 terlihat pembawa acara sedang memasang dan mengunci ayakan mesh sesuai dengan posisinya. Adapun pemeragaan yang dilakukan oleh pembawa acara dimulai dari menghidupkan power alat dan memastikan mesh dalam keadaan bersih. Kemudian pembawa acara mengunci mesh pada bagian atas alat. Setelah terkunci maka pembawa acara mengatur kecepatan ayakan dan memulai ayakan. Pemeragaan ini dilakukan oleh pembawa acara sembari mengucapkan atau memberi tahu kepada penonton prosedur yang ia lakukan seperti pada gambar 7. Kombinasi antara memeragaan dan suara diharapkan penonton akan lebih mengerti dan materi dapat sampai ke penonton.

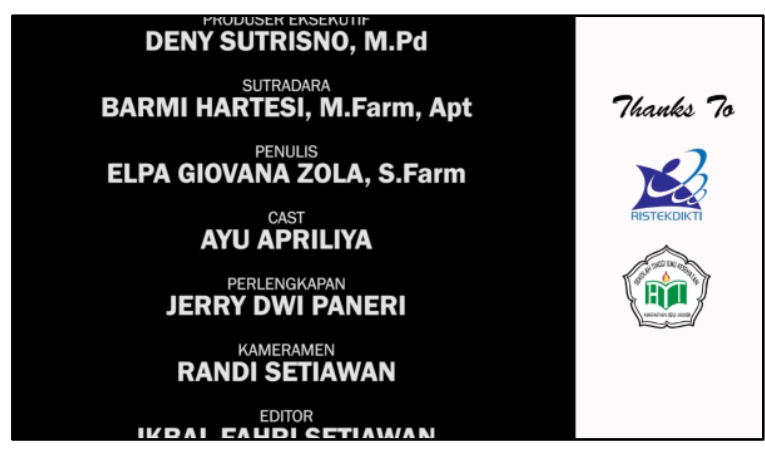

Gambar 7. Potongan Gambar Bagian Penutup

Diakhir video ditampilkan nama-nama tim pembuatan video. Nama-nama tim pembuatan video pembelajaran ini seperti yang terlihat pada gambar 8. Komposisi tim ini terdiri dari produser eksekutif, sutradara, penulis, pemeran, perlengkapan, pengambil dan penyunting gambar dan suara.

Tabel 2. Hasil Angket Respon Video Penggunaan Ayakan Bertingkat

\begin{tabular}{lc}
\hline \multicolumn{1}{c}{ Butir Item } & $\begin{array}{c}\text { Persentase } \\
\text { Jawaban } \\
\text { "Ya" }\end{array}$ \\
\hline $\begin{array}{l}\text { Memahami materi yang } \\
\text { disajikan }\end{array}$ & $93 \%$ \\
\hline $\begin{array}{l}\text { Merasa tampilan (gambar, } \\
\text { warna, animasi, dll) telah } \\
\text { baik }\end{array}$ & $78,9 \%$ \\
\hline $\begin{array}{l}\text { Berminat untuk mengikuti } \\
\text { kegiatan belajar }\end{array}$ & $89,5 \%$ \\
\hline $\begin{array}{l}\text { Menilai materi telah cukup } \\
\text { baik }\end{array}$ & $98,2 \%$ \\
\hline $\begin{array}{l}\text { Merasakan manfaat } \\
\text { penggunaan media video }\end{array}$ & $96,5 \%$ \\
\hline $\begin{array}{l}\text { Merasa perlunya materi yang } \\
\text { lain perlu disajikan seperti ini }\end{array}$ & $91,2 \%$ \\
\hline $\begin{array}{l}\text { Membutuhkan materi perlu } \\
\text { dijelaskan kembali oleh } \\
\text { dosen }\end{array}$ & \\
\hline
\end{tabular}

Video dipertontonkan ke mahasiswa semester 1 Program Studi Farmasi STIKES 
Harapan Ibu Jambi untuk mendapatkan umpan balik. Pengambilan umpan balik mengenai keberhasilan video ini dilakukan kepada 57 mahasiswa. Hasil umpan balik pada tabel 2 terlihat secara umum video pembelajaran ini dapat dikatakan sudah cukup baik. Bahkan 91,2\% merasa perlu materi lainnya disajikan seperti ini. Karena jika pembelajaran menggunakan media video mahasiswa juga akan puas dan termotivasi ingin melanjutkan lagi (Larkin-hein \& Zollman, 2000; Moemennasab, Rahemi, Ayatollahi, \& Aeen, 2002). Video akan lebih baik lagi pada mahasiswa jika terdapat kegiatan analisis (Asrizal, Yohandri, \& Kamus, 2018). Secara keseluruhan terlihat seluruh item memperoleh nilai diatas $78 \%$

Akan tetapi pada hasil angket $89,5 \%$ mahasiswa masih membutuhkan penjelasan lebih lanjut oleh dosen. Walaupun begitu penggunaan video pembelajaran akan dapat membantu bagi dosen atau pun laboran (Sindu \& Paramartha, 2018). Penggunaan berbagai media pembelajaran akan diperlukan dalam memberikan kuliah.Video pembelajaran dapat digunakan sebagai pelengkap dari metode pembelajaran blended learning untuk mengkombinasikan antara tatap muka lansung dan cara daring (Fahrurozi, Maryono, \& Budiyanto, 2017). Oleh karena itu setelah diperlihatkan video pembelajaran ini maka dosen perlu menambahkan penjelasan-penjelasan yang dianggap perlu dan juga perlu dibuka sesi tanya jawab mengenai isi video pembelajaran agar maksud isi video dapat tersampaikan.

Video pembelajaran juga dapat ditampilkan melalui platform lain untuk dapat diakses mahasiswa (Kholifah, 2016). Oleh karena itu video ini diunggah melalui platform media sosial Youtube sehingga dapat selalu diakses oleh mahasiswa. Hal tersebut dilakukan karena pada saat ini mahasiswa sering mengakses media sosial dan juga dapat diakses dimana saja (Kesici, 2019; Suarez Sarmiento \& Macias Lopez, 2012). Media sosial sangat populer di kalangan mahasiswa sehingga dapat dimanfaatkan oleh dosen sebagai media pembelajaran (Dogari \& Apuke, 2019). Pada saat proses pengambilan umpan balik peneliti tidak mengalami kesulitan dalam mengarahkan mahasiswa untuk membuka video yang diunggah. Hal ini menandakan tempat media pembelajaran diunggah cukup dikenal bagi mahasiswa.

\section{KESIMPULAN}

Pembuatan video pembelajaran dalam bentuk tutorial pengunaan ayakan bertingkat dapat dibuat dengan mengkombinasikan gambar dan tulisan. Alur video diawali dengan pembukaan dan dilanjutkan dengan perkenalan bagian alat lalu pemeragaan cara pengunaan alat ayakan bertingkat. Hasil umpan balik mahasiswa memperlihatkan bahwa video telah baik akan tetapi mahasiswa masih membutuhkan penjelasan lebih lanjut dari dosen pengampu agar lebih memahami materi dari video pembelajaran. Hasil dari pengembangan video pembelajaran ini adalah video yang diunggah ke sosial media sehingga dapat diakses oleh mahasiswa.

\section{DAFTAR PUSTAKA}

Agustina, \& Alviya. (2012). Pengembangan Media Pembelajaran Video Untuk Melatih Kemampuan Memecahkan Masalah Pada Materi Larutan Asam Basa (Development of Learning Media Experience To Win Chemistry Based On Computer For Orientation Problem Solving At Acid Base Solution). UNESA Journal of Chemical Education, 1(1). Retrieved from http://ejournal.unesa.ac.id/index.php/journal-ofchemical-education/article/view/149

Asrizal, A., Yohandri, Y., \& Kamus, Z. (2018). Studi Hasil Pelatihan Analisis Video dan Tool Pemodelan Tracker pada Guru MGMP Fisika Kabupaten Agam. Jurnal Eksakta Pendidikan (JEP), 2(1), 41. https://doi.org/10.24036/jep/vol2iss $1 / 84$

Dogari, K. A., \& Apuke, O. D. (2019). The prospects and constraints of integrating social media into the Nigerian Higher Educational System: Students' and lecturers' perspectives. Turkish Online Journal of Distance Education, 20(2), 162-175. https://doi.org/10.17718/tojde.557861 
Fahrurozi, S. K., Maryono, D., \& Budiyanto, C. W. (2017). The Development of Video Learning to Deliver a Basic Algorithm Learning. IJIE (Indonesian Journal of Informatics Education), 1(2), 135-142. https://doi.org/10.20961/IJIE.V1I2.124 46

Isti, Z.-. (2012). Meningkatkan Kemampuan Penjumlahan Bilangan 1-20 Melalui Model Pembelajaran Creative Problem Solving Dengan Video Compact Disk (VCD) Pada Anak Tunarungu. Jurnal Penelitian Pendidikan Khusus, 1(2). Retrieved from http://ejournal.unp.ac.id/index.php/jupekhu/article/view/848/705

Kesici, A. (2019). Do social students use social media more often? Turkish Online Journal of Distance Education, 20(2), 121-133. https://doi.org/10.17718/tojde.557855

Kholifah, S. (2016). The Development of Learning Video Media Based on Swishmax and Screencast O-Matic Software through Contextual Approach. Dinamika Pendidikan, 11(1), 67-74. https://doi.org/10.15294/dp.v11i1.8701

Larkin-hein, T., \& Zollman, D. A. (2000). Digital video, learning styles, and student understanding of kinematics graphs. Journal of SMET Education, 1(2), 17-30. Retrieved from http://ojs.jstem.org/index.php/JSTEM/article/view/1163

Moemennasab, M., Rahemi, S., Ayatollahi, A., \& Aeen, M. (2002). The effect of video-based instruction on students' cognitive learning. Journal of Medical Education, $1(3)$. https://doi.org/10.22037/JME.V1I3.948

Moskal, P., Dziuban, C., \& Hartman, J. (2013). Blended learning: A dangerous idea? Internet and Higher Education. https://doi.org/10.1016/j.iheduc.2012.1 2.001
Pebriani, C. (2017). Pengaruh penggunaan media video terhadap motivasi dan hasil belajar kognitif pembelajaran IPA kelas V. Jurnal Prima Edukasia, 5(1), 11-21. https://doi.org/10.21831/JPE.V5I1.846 1

Setiawan, R. (2015). The Difference of Motivation and Social Science Achievement with the Learning Application of STAD Video Media and STAD nonvideo. Jurnal Pendidikan Humaniora, 2(2), 112-117. Retrieved from http://journal.um.ac.id/index.php/jph/article/view/4450

Sindu, I. G. P., \& Paramartha, A. A. G. Y. (2018). The Effect of the Instructional Media Based on Lecture Video and Slide Synchronization System on Statistics Learning Achievement. SHS Web of Conferences, 42, 00073. https://doi.org/10.1051/SHSCONF/201 84200073

Suarez Sarmiento, A., \& Macias Lopez, E. (2012). Multimedia services and streaming for mobile devices: challenges and innovation. 329. Retrieved from https://ieeexplore.ieee.org/abstract/document/5374365/

Sugandi, M. (2012). Pengajaran Case Based Learning Audio Video Pada Matakuliah Manajemen Konstruksi Bagi Mahasiswa Program Studi Teknik Sipil. Teknologi Dan Kejuruan, 28(2). https://doi.org/10.17977/TK.V28I2.311 0

Syarif, I. (2012). Pengaruh Model Blended Learning terhadap Motivasi Dan Prestasi Belajar Siswa SMK. Jurnal Pendidikan Vokasi, $2(2)$. https://doi.org/10.21831/jpv.v2i2.1034

Yamasari, Y. (2010). Pengembangan Media Pembelajaran Matematika Berbasis ICT yang Berkualitas. Seminar Nasional Pascasarjana $X$ - ITS. Surabaya. 